\title{
Where Are We Now?
}

\author{
Kas Oosterhuis \\ Researcher-Qatar University, Emeritus Professor TU Delft \\ Director ONL \\ oosterhuis@oosterhuis.nl
}

After 16 years of leading the Hyperbody research group as professor of practice at the TU Delft, I wanted to do something completely different and looked at the Gulf region for further educational and professional activities. I was familiar with the region, having lectured in several countries of the Middle East and eventually having realized an office building in Abu Dhabi. My practice ONL [Oosterhuis_Lénárd], which I run together with my wife and business partner visual artist Ilona Lénárd, proposed a number of iconic architectural proposals for hotels and office towers, and was eventually awarded some prestigious commissions for master planning projects: the redevelopment of Manhal Palace, the residence of previous ruler Sheik Zayed in Abu Dhabi. Our continuous efforts to contribute to the building market in the UAE culminated in our realized design for Mr Abdullah Al Nasser, the LIWA tower in Abu Dhabi [2014]. I Joined the Department of Architecture and Urban Planning [DAUP] at Qatar University in September 2017.

\section{Featured Realized Projects}

My future has always coalesced with the here and now. Many consider my projects to be futuristic, but for me they are the ultimate daily reality, taking advantage of the technological and social achievements of the day, as reflected in my featured projects the Saltwater pavilion [Neeltje Jans, 1997], Web of NorthHolland [Haarlemmermeer, 2002], A2 Cockpit [Utrecht, 2005], the Bálna Budapest [Budapest, 2013], and the Liwa Tower [Abu Dhabi, 2014]. These internationally widely published projects are typically based on the paradigm shift in design practice from $3 \mathrm{~d}$ modelling to parametric design and the other paradigm shift from mass production of series of the same to mass customization of series of unique building components. An important source of inspiration are complex adaptive systems like swarms of starlings, fascinated as we are by the ever changing configurations of the swarm. We have successfully implemented the principles of the swarm to the way building components are flocking together in the dynamic complex adaptive design systems and the direct file to factory link from the parametric design scripts to robotic CNC controlled production [Figure 1].

\section{Design Methods ARCT 320 Fall 2017}

The first project visual artist Ilona Lénárd and I did was the Design Methods and Theories course. One of the things we asked the students is to make a painting that expresses their emotions, without any reference to nature or existing products. No portraits, no trees, no animals, no houses, cars, no coffee cups. We taught them to express abstract ideas that were waiting to be set free. We believe that abstract design thinking is essential to become an architect or artist, since you will need to construct a new reality, which has not been there before. We asked them to put their individual paintings together to form a larger painting, thus stimulating teamwork and creating shared values [Figure 2].

\section{ICE Café Interactive Public Art}

In the meantime, in fall 2017 I wrote several research proposals, internal grants for a smaller research project, and through QNRF for NPRP grant. Three proposals were rewarded, the GSM4Q conference, the QU MANIC research for Multimodal Accommodation for the Nomadic International Citizen and the NPRP Qatar Robotic Printing project. We developed together with a team around the Head of Department Dr Fodil Fadli, a concept for an Interactive towering structure, to be located in front of the entrance of the College of Engineering B09 Building, functioning as a coffee shop and an iconic public art structure to represent 
the dynamic nature of the College. The Interactive ICE Café tower would swing and rotate in its entirety to have a life of its own. The $16 \mathrm{~m}$ high tower would bend itself in the direction of prevailing winds as to catch a breeze and bring down the breeze all the way down the coffee shop on ground level [Figure 3].

\section{Maidan Monument}

Together with a team of Qatar based artists and QU architect-researchers, we joined an international competition for a public art project in Kiev. The brief was to design a monument for the Hundred Heavenly Heroes, those who gave their life in the 2015 revolution. The images of the Maidan Revolution of 20142015 have made a deep impression in the world, the photos of the dramatic sceneries, especially the night views went all over the world. Our design team has chosen to take the flag as the virtual carrier of the geometry of the Maidan monument. An imaginary volume of a waving flag is populated with exactly hundreds points/nodes, each of them representing one of the hundred heroes. The nodes form a spatial three-dimensional network, therewith representing the mutual connectivity and the robust collaboration between the heroic people, whether they belong to the heavenly hundred or to the thousands of their fellow protesters [Figure 4].

\section{Machining Emotion Robotic Workshop}

One of the most rewarding experiences during our stay in Doha was the conceptualization and execution of the robotic workshop. Together with Ilona we had previous experience with a robotic painting project titled Machining Emotion, using a large robot arm to produce a workflow merging intuitive painting with scripting algorithms and robotic execution of the paintings. We teamed up together with Dr John John Cabibihan from MIE (Mechanical and Industrial Engineering) Department at College of Engineering to offer a robotic workshop at Doha Fire Station, open for students of Qatar University and artists in residence of Fire Station. There was one smaller humanoid robot, another very slow pick and place robot, we had a few simple drones, and we bought some vacuum cleaning robots to play with. We realized two large ground-based paintings, one additive painting, adding acrylic paint to a large canvas of $2 \times 10 \mathrm{~m}$, and one subtractive painting of the same dimensions. For this one, we flooded the working area with flour that was to be sucked up by the cleaning bots [Figure 5].

\section{Multimodal Accommodations for the New International Citizen [MANIC]}

The MANIC research builds upon earlier studies by the Dutch architect John Habraken on open building architecture providing for flexibility in use of the homes [N.J. Habraken, Supports: Alternatives for Mass Housing, 1972], and on the visionary art project New Babylon by the Dutch Artist Constant Nieuwenhuys [catalogue New Babylon, Haags Gemeentemuseum, 1974] In New York, in 1980's, the concept of the loft' became popular. The MANIC research takes the loft concept and New Babylon to a new level, by introducing programmable interior furniture and fit-out as to transform in real time the available space into different types of usage, as spacious as possible, programming the $50 \mathrm{~m} 2$ unit to become a bathroom, a bedroom, a living room, kitchen or as an empty space of $50 \mathrm{~m} 2$ for yoga sessions. Multimodal Accommodations facilitate the Nomadic International Citizen [MANIC]. Each individual spatial unit may be booked for a different function and for any period of time. The ubiquitous booking system facilitates the nomadic 21 st century international citizen [Figure 6]

\section{West Bay North Beach Master Plan}

I taught at the Architectural Association in the years 1988 - 1989. In my unit I had one student from Qatar. After 30+ years I met Badria Kafood again in the DECC where she had a stand with her own architectural office. I asked her to team up with us to submit a design for the West Bay North Beach competition published by Ashghal. Our concept for West Bay North Beach [WBNB] master plan aims at interweaving the generic with the iconic. The generic buildings are meant to be able to design and build within a very short period of time as to be ready by 2022 . The iconic buildings on the triangular islands are meant to form the attractors 
to comply with Qatar Vision 2030 and will be developed between 2022 and 2030. The Generic Towers; the triangular treasure island containing the leisure parks and the landmark buildings are connected by a smooth network of elevated traverses, providing shade and comfort for the pedestrian. The traverses connect the Generic Towers to each other and the existing area of West Bay North Beach to the new developments extending into the bay of Doha. Inserted between the existing towers at West Bay North Beach area, the master plan foresees the realization of a few striking urban farming Food Towers, providing for food to be produced and consumed locally in West Bay [Figure 7].

\section{Little Babylon Interactive Sculpture}

Rezone of the Netherlands has been the client for the inflatable Mothership sculpture called Little Babylon, which I designed in a team with the Air Design Studio, and the app developers Marijn Moerbeek and Thomas Rutgers for the interaction. We installed Little Babylon at Doha Fire Station and later at Qatar University Library during GSM4Q conference. Mothership Little Babylon communicates this data with the audience in an interactive way as a dynamic, audio-visual performance. It adds a digital, emotional and social layer to a current urban condition. The pavilion personifies the digital city and mines twitter for specific topics and translates this data in movement, visuals and sound, which together show the sentiment and temperament of the specific city [Figure 8].

\section{Public Art | ARCT 120}

In fall 2018, I taught the ARCT 120 Introduction to Architecture and Allied Arts to first year students. The first brief was to choose a household object [coffee machine, vacuum cleaner, mobile phone holder] and dissect it into its parts. Then I asked them to draw these parts as if they were the designer. I asked them to show how the parts work together to form the working device. Later, I requested them to describe how the parts were made, what materials were used and how these were produced. The next task I gave them was to analyze parts of a car and the context they were in. I asked to focus on headlights, look at them from all angles, model them and draw them. In this way they learned how a complex project like a building actually is a composition of different parts that are designed to fit exactly together to form the house. Finally, I asked them to design a substantially large piece of public art and make a $1: 10$ scale model on a $60 \mathrm{x} 60 \mathrm{~cm}$ ground plate [Figure 9].

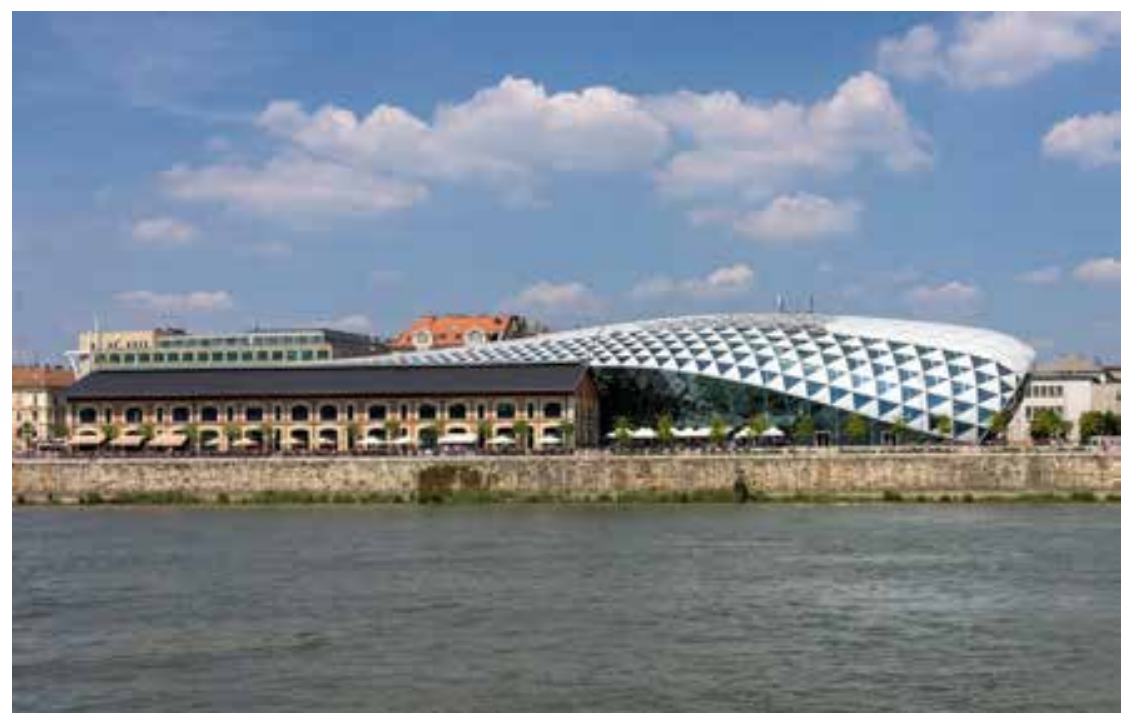

Figure 1: | Bálna Budapest | design ONL / Kas Oosterhuis | Budapest 2014. 


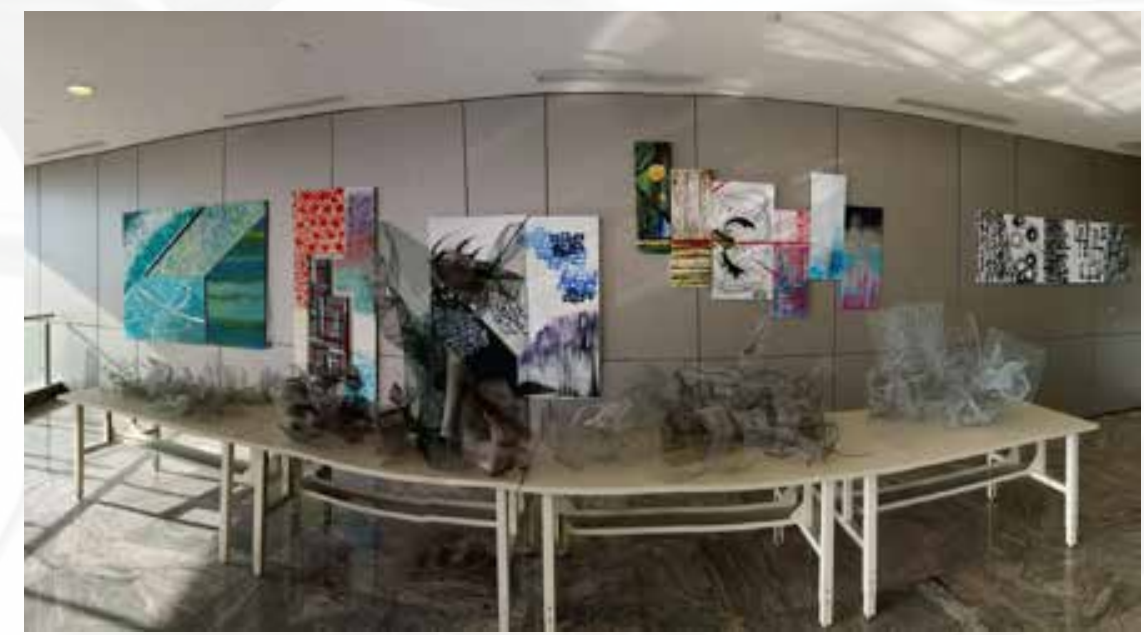

Figure 02: | ARCT 320: Design Methods and Theories course | tutors Kas Oosterhuis and support artist (Ilona Lénárd) | QU DAUP Fall 2017.

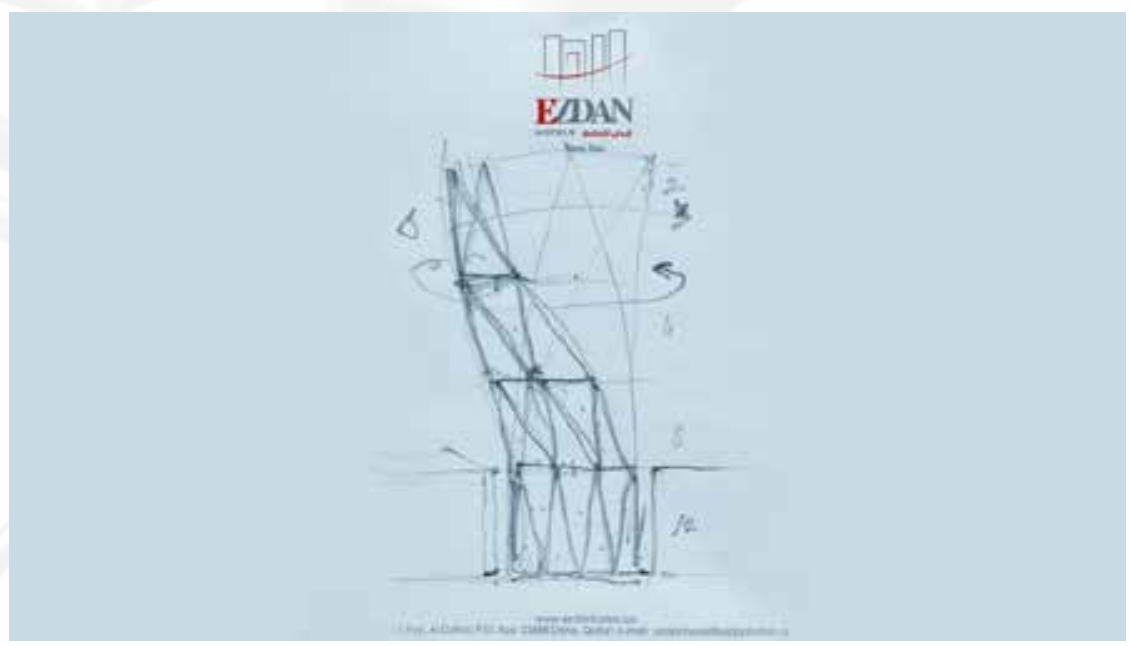

Figure 03: | ICE Café interactive Tower | initial sketch by Kas Oosterhuis | 2017.

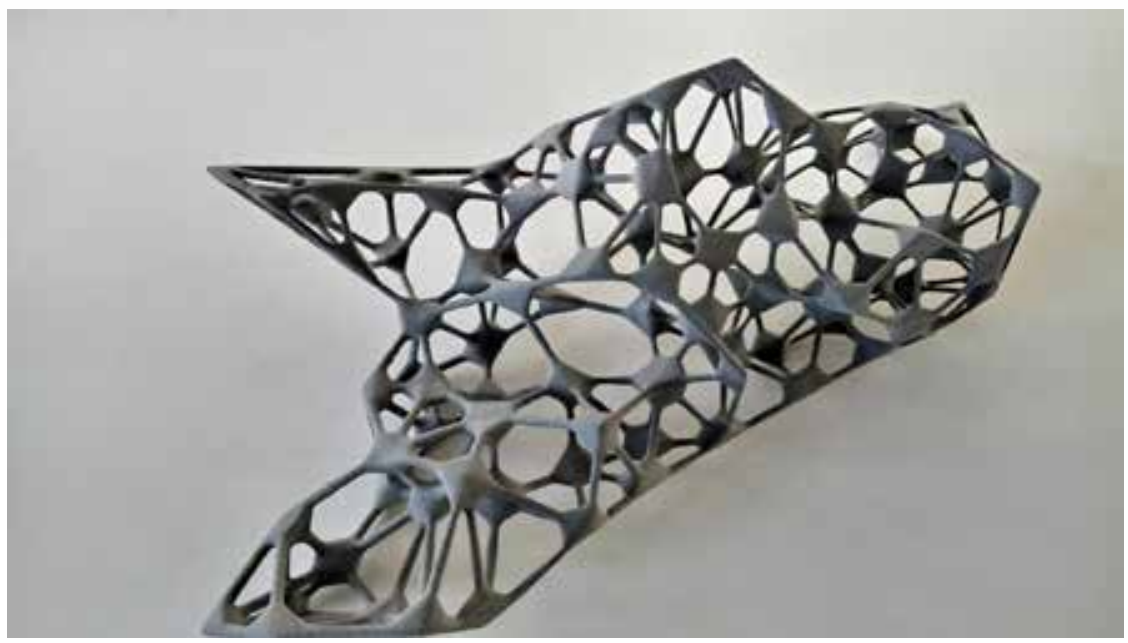

Figure 04 | Maidan Monument | Kiev | design team Kas Oosterhuis, Ilona Lénárd, Yassmin Alkhasawneh, Najeeba Kutty,Diogo Esteves | 2018. 


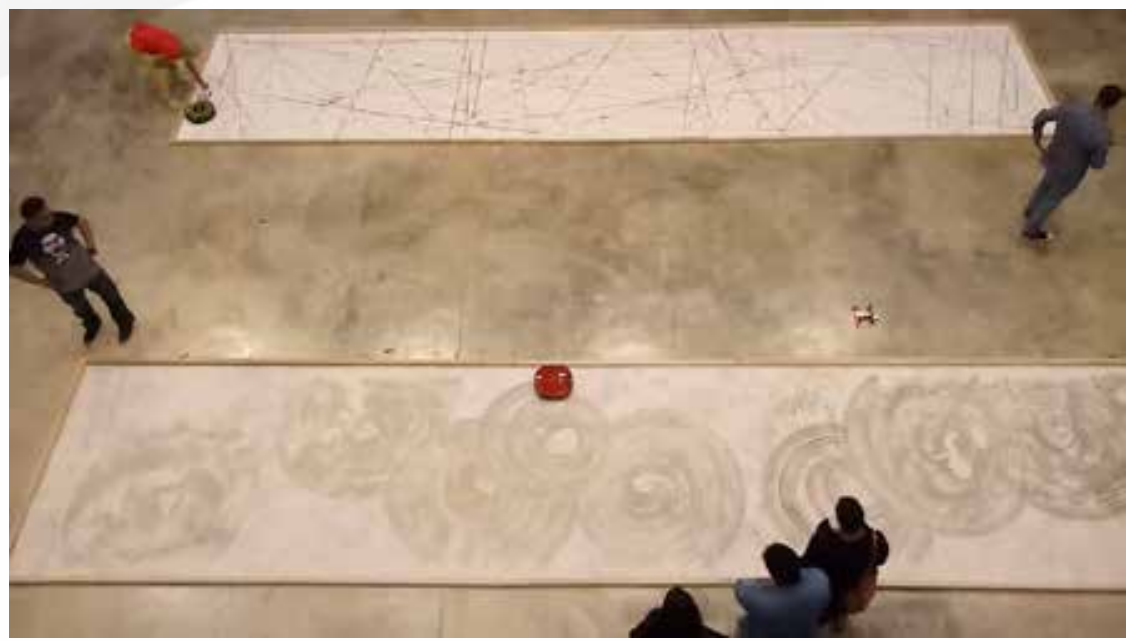

Figure 05: | Machining Emotion robotic workshop | overview additive and subtractive painting | Doha Fire Station Workshop 4 | 2018.

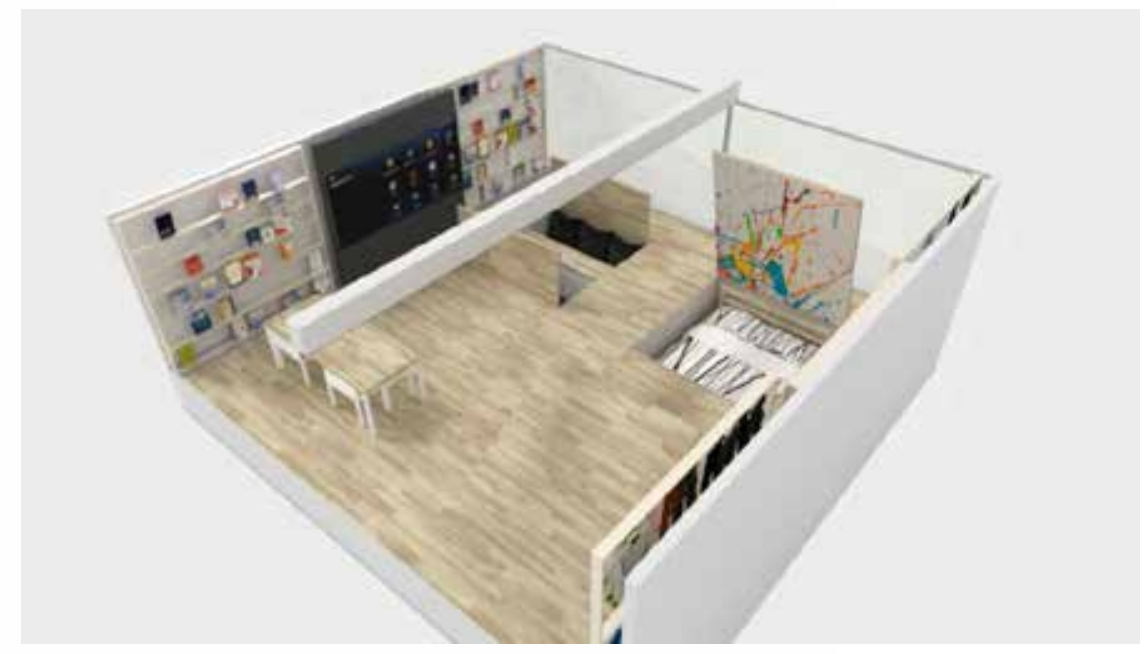

Figure 06: | Multimodal Accommodations for the New International Citizen [MANIC] | researcher Kas Oosterhuis 2018.

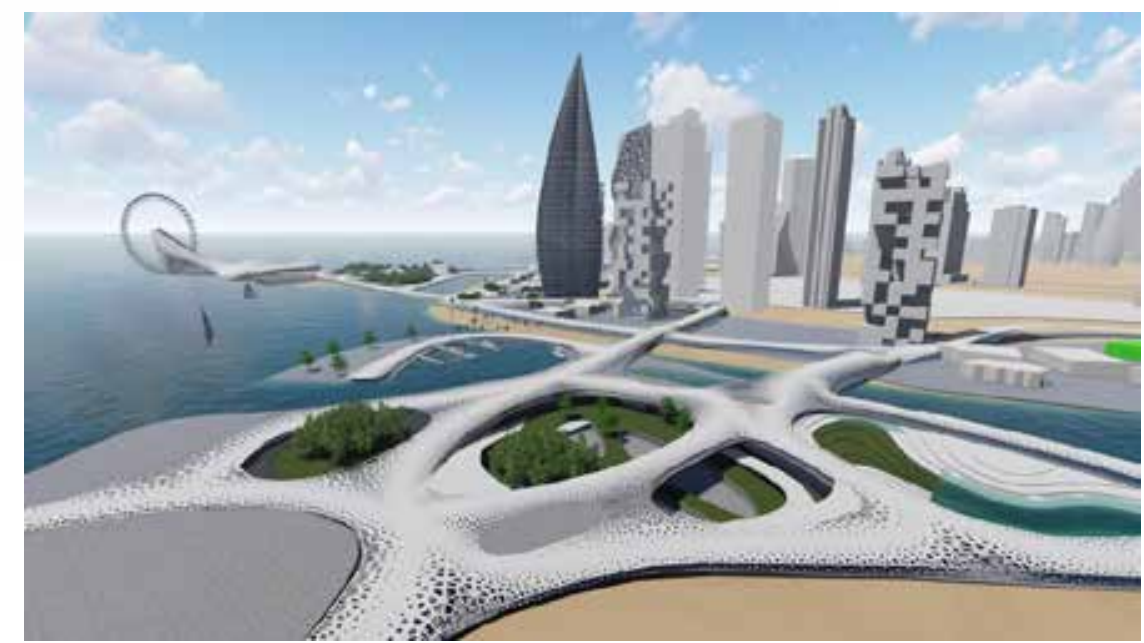

Figure 07: | West Bay North Beach | master plan by Kas Oosterhuis / Doha architect Badria Kafood | 2018. 


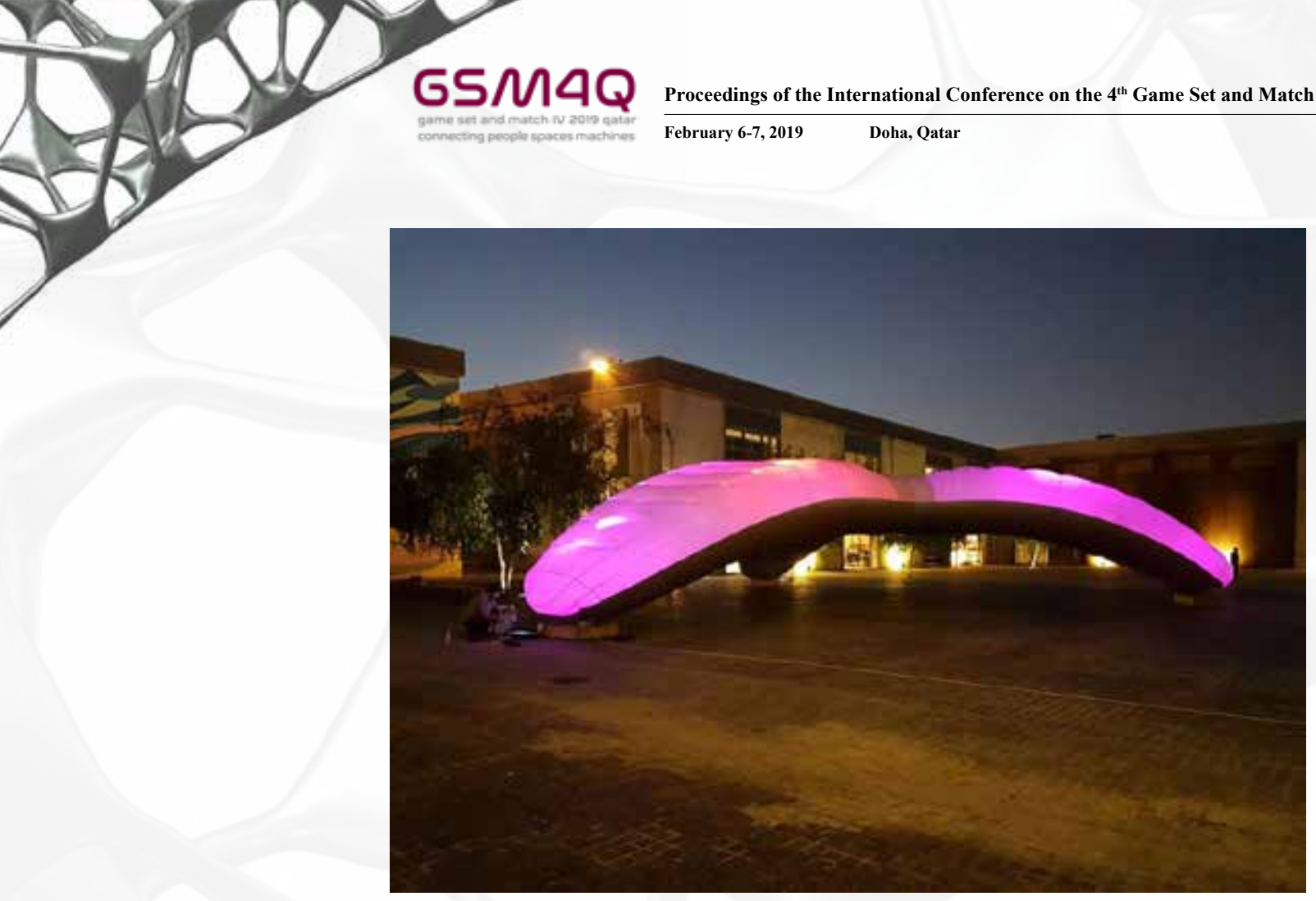

Figure 08: | Mothership Little Babylon | design ONL / Kas Oosterhuis | Doha Fire Station 2018.

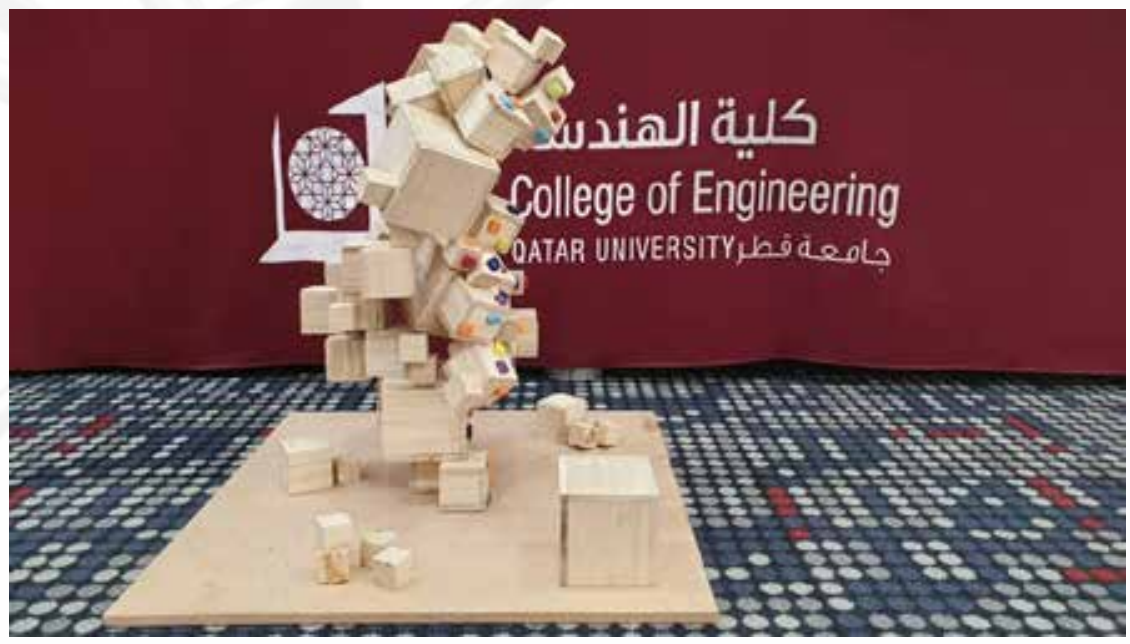

Figure 09: | ARCT 120 Introduction to Architecture and Allied Art public art project 1:10 scale model by first year student | Fall 2018.

Cite this article as: Oosterhuis K., "Where Are We Now?", International Conference on the $4^{\text {th }}$ Game Set and Match (GSM4Q-2019), Doha, Qatar, 6-7 February 2019, https://doi.org/10.29117/gsm4q.2019.0025 